\title{
METHODOLOGICAL ASPECTS OF AUTOMATIC PILOT FLIGHT ASSESSMENT SYSTEM
}

\author{
Tadas Masiulionis ${ }^{1}$, Jonas Stankūnas ${ }^{2}$ \\ Department of Avionics, Antanas Gustaitis Aviation Institute, Vilnius Gediminas Technical University, \\ Rodūnios kelias 30, LT-02187 Vilnius, Lithuania \\ E-mails: ${ }^{1}$ Tadas.Masiulionis@vgtu.lt (corresponding author); ${ }^{2}$ Jonas.Stankunas@vgtu.lt.
}

Received 11 April 2013; accepted 03 September 2013

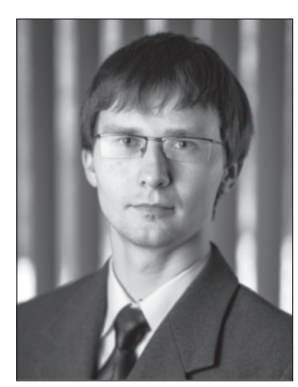

Tadas MASIULIONIS, $P h D$.

Date and place of birth: 1984 in Vilnius, Lithuania.

Education: Antanas Gustaitis Aviation Institute of Vilnius Gediminas Technical University, master, 2011.

Affiliations and Functions: 2010-2012 - Aviation mechanic/avionic, Periodic maintenance department at FL Technics corp.; 2012-until now - PhD/assistant,

Department of Avionics of Antanas Gustaitis Aviation Institute at Vilnius Gediminas

Technical University.

Research interests: electronics and electric engineering.

Publications: author or co-author of 4 scientific articles, 4 scientific reports.

Present position: assistant of Department of Avionics at Vilnius Gediminas Technical University.

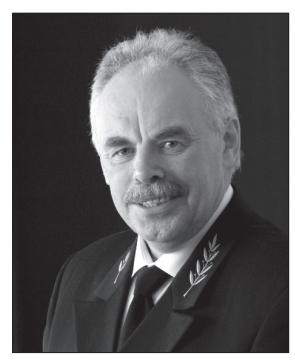

Jonas STANKŪNAS, Prof. Dr Habil.

Date and place of birth: 1949 in Pakene, Rokiškis District, Lithuania.

Education: 1970 - Krivoj Rog Civil Aviation School, Ukraine; 1976 - Faculty of

Automation at Vilnius Institute of Civil Engineering; 1981 - post-graduate studies at Vilnius Institute of Civil Engineering.

Affiliations and Functions: 1970-1972 - aviation technician; Vilnius Joint Aviation

Platoon: 1972-1975 - expert, Radio Apparatus Technology Dept.; 1975-1978 -

senior engineer, Scientific Research Sector; 1982-1987 - head of science laboratory

of slow wave and deflecting systems, Vilnius Institute of Civil Engineering;

1988-1993 - Assoc. Professor, Radio Apparatus Technology Department, Vilnius

Technical University (formerly Vilnius Civil Eng. Institute) and Kaunas University

of Technology (formerly Kaunas Polytechnic institute); since 1993 - director of

Antanas Gustaitis Aviation Institute (AGAI) of Vilnius Gediminas Technical University; 1993-1995 - Assoc. Professor; 1995 - Dr Habil; 1995-1997 - Professor,

Air Traffic Control Department (AGA1); since 1997 - Professor, Avionics Department (AGAI); vice chairman of Council of Lithuanian National Aeronautical Technology Platform: delegate of the Republic of Lithuanian at the Specific Program Committee 'Cooperation', theme 'Transport (including Aeronautics)'; member of Advisory Council for Aeronautics Research in Europe (ACARE).

Research interests: electronics and electric engineering.

Awards: winner of Lithuanian State Award in Technological Sciences, 1997.

Publications: author or co-author of 143 scientific articles, 4 monographs, 31 reports, 97 scientific reports, and 9 educational methodological publications; inventions: creator or co-creator of 14 inventions; training: advancement training in Great Britain, Canada and Sweden. 
Abstract. This article deals with the various aspects of automatic pilot flight assessment system methods. Different types of flight corridors are examined: circling, left and right superelevation drawing (number eight), and others. The advantages and disadvantages of each of them are discussed. Limit line calculations of the corridor turns are presented. The aim is to develop new flight assessment methods.

Keywords: aviation, assessment of flight training, flight training, automated flight accuracy assessment, flight assessment methodology.

\section{Introduction}

The problem of knowledge assessment is one of the most difficult sides of pedagogical work. The most important objectives for this phase of training are simple and clear: the teacher must witness the achieved student proficiency level of a particular subject and has to do it objectively. But just considering the achievement of these two simple goals, let alone sitting down to the examiner's chair, one is faced with dozens of questions (Lobanova 1997).

Assessment is objective only when performed according to predefined criteria. The same objectivity is also necessary for assessment of training flights. Assessment of some flight criteria can be accomplished by an automated pilot flight assessment system (Stankūnas 1997).

\section{Methods of automatic pilot flight assessment system}

Most scientists analyse various ways of displaying flight corridors in cockpits or in flight training simulator screens (Bourgois et al. 2005). In a flight assessment system these corridors are invisible for pilot, because they are used only as limits according to which the pilot's flight is assessed. Such a corridor may only be seen when analysing a pilot's flight.

Prior to the development of such a system, it is important to analyse according to what criteria pilots are assessed and which of these criteria can be evaluated by the assessment system. Therefore, the following list presents various criteria and parameters that could be used by an automatic flight assessment system.

Pilot assessment criteria:

- recording of fly-over point times;

- horizontal deviation from a set track line;

- vertical deviation from a set track line;

- speed retention;

- horizontal flight stability;

- vertical flight stability.

Aircraft parameters:

- aircraft wingspan;

- aircraft length;

- aircraft height;

- location of antenna on the aircraft as the starting point of measurement.

\section{Runway parameters:}

- length;

- width;

- longitude coordinate;

- latitude coordinate;

- angle from the True North pole.

The ability to change the following parameters in the flight corridor:

- corridor length;

- corridor width;

- corridor height;

- corridor turning radius;

- position of turning corners in the airspace;

- height and width of valid board of corridor.

Such a pilot flight assessment system could be applied to any existing aerodrome in the world since by entering into a system the desired aerodrome and selected flight corridor parameters, an imaginable assessment corridor would be created.

Several possible variants of development of flight assessment corridors have been described. A cylindrical corridor has been offered as one of them (Savičienè 2011). An example of cylindrical flight assessment corridor is provided in figure 1 .

A flight would be assessed by measuring the radius of the cylinder, in which the centre of the circle would be set as the flight trajectory.

If the pilot's aircraft departed out of certain assessment cylinder boundaries, pilot flight rating would decrease.

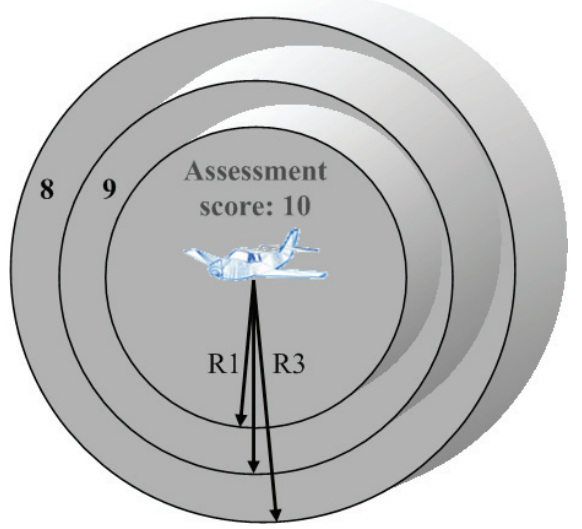

Fig. 1. Cylindrical pilot flight assessment corridor

Rectangular corridors are also used for flight trajectory visualization. Such corridors are used in flight training simulators, in which flight trajectory and land- 
ing path are visualized (Bahcivan et al. 2011). This corridor is also used in HUD (Head-Up Display) systems (Funabiki, Iijima 2007). If a rectangular corridor was used for assessment of pilot's flight, it could be divided into smaller separate rectangulars for assessment of both horizontal and vertical flight. This type of assessment corridor is illustrated in figure 2 below.

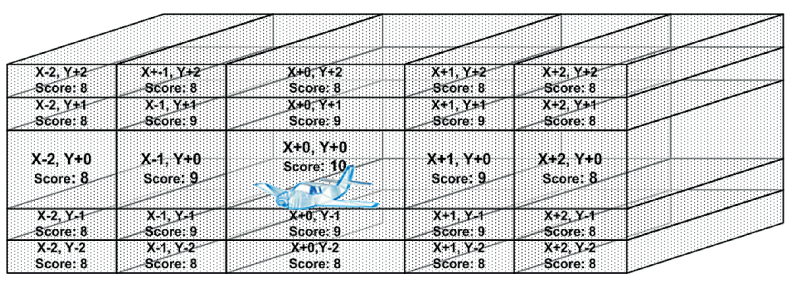

Fig. 2. Division and distribution of rectangular pilot flight assessment corridor according to assessment scores

Figure 3 illustrates a vertical projection of rectangular flight corridor near runway.

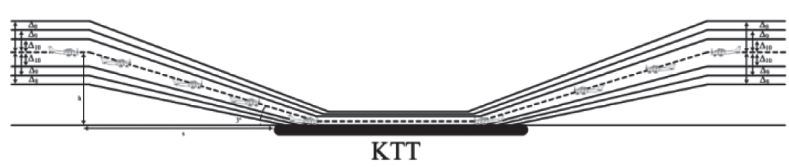

Fig. 3. Vertical corridor for pilot flight assessment on the runway

Assessment in this corridor is performed in the same way taking into consideration deviation criteria $\Delta$ of trajectory (Fig. 4). The main difference is that on the runway the deviation of landing path, which narrows when approaching the runway, must be assessed; therefore, requirements for aircraft pilot flight accuracy are higher. When an aircraft touches the base of the runway, aircraft persistence over runway longitudinal line and aircraft stability taxing on the runway would be monitored.

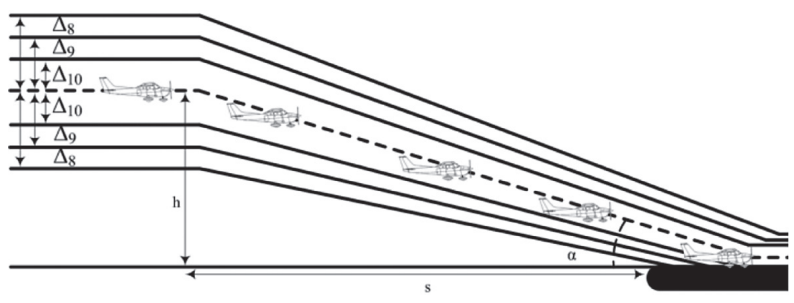

Fig. 4. Descent trajectory approaching runway

The onset of the landing path depends on height $h$, at which the pilot is flying. Therefore, the landing path distance $s$ in relation to the terrain may be calculated according to equation (1) provided below:

$$
s=\frac{h}{\tan \alpha} ;
$$

where $h$ is set corridor height; $\alpha$ - landing path angle, which is usually $3^{\circ}$.
Moreover, the landing path onset in relation to the runway may vary, if the landing path angle in relation to the terrain is not $3^{\circ}$. Therefore, after entering variables into the pilot flight assessment system, it could calculate and assess these distances.

When solving issues concerning pilot assessment during circuit flight, the shape of turns has to be decided. The limit line of each turn assessment may be drawn according to arcs of same length radius $R$ (Fig. 5). However, this way the flight assessment corridor becomes complex and complicated, since the coordinates of all axes of arcs radius are different. Moreover, in order to calculate them, more time and resources will be needed since all axes points will have to be connected to each other and finally to be linked with runway coordinates.

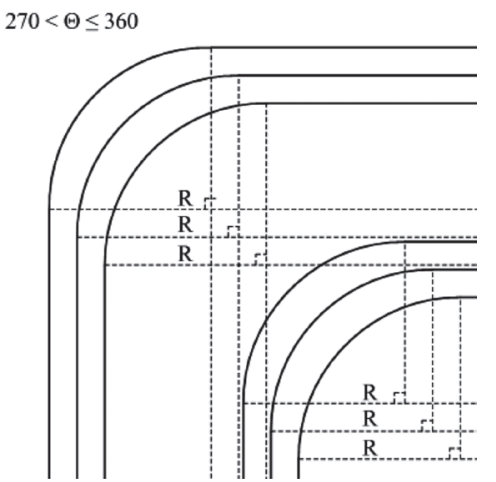

Fig. 5. Pilot flight assessment of the corridor turns when turn radius are of the same length

However, a simpler solution has been found. A. Herdon in his paper presents a single centre point radius flight corridor (Herndon et al. 2008). According to his suggestion, figure 6 illustrates an improved pilot flight turn assessment corridor. This method corresponds better to a real aircraft turn and simplifies calculation of corridor limit lines (arc's radiuses) and the linking of these arcs axes with runway coordinates.

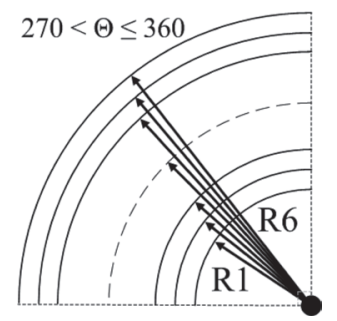

Fig. 6. Pilot flight assessment corridor turns with a single centre point

Aircraft deviation from set trajectory during turns may be calculated according to equations (2) and (3) provided below:

$$
\begin{aligned}
& x=R \cdot \cos \theta ; \\
& y=R \cdot \sin \theta .
\end{aligned}
$$


When calculating lengths of arcs radius, it can be determined, whether the aircraft is still within the limits of set flight corridor from the available aircraft coordinates $x$ and $y$, according to equation (4):

$$
c=\sqrt{x^{2}+y^{2}} \text {. }
$$

Figure 7 illustrates the whole flight corridor of circuit flight. All corridor turns arc radius axes and linear flight assessment zones are linked to runway centre point coordinates, which are the starting point of measurement and calculation for the whole corridor.

Usually during training flights the most important are the landing path and runway zones. These are practices most by the students. However, using the flight corridor presented in figure 7 , the pilot flight in the whole flight corridor could be assessed. Additionally, flight time could be assessed as well, e.g. a pilot at certain time moments should as accurately as possible fly over determined fly-over points (check points). Fly-over points could be either the circular flight turns or various onground objects in straight flight trajectory.

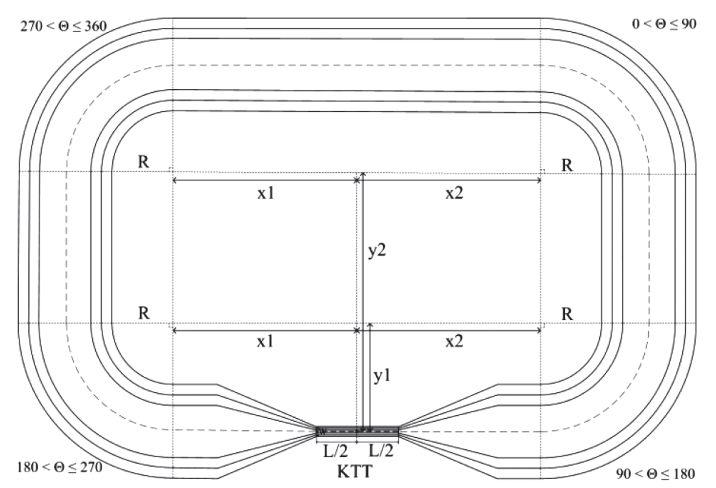

Fig. 7. The assessment corridor of circuit flight with rounded turns

During training, in order to economize aircraft fuel consumption and flight time, pilots often start approaching to land from the third turning point. Therefore, this assessment methodology is more appropriate for the assessment of flight examination, when the pilot should fly around the entire circle of flight.

Researching on training flights focuses on several ways of flying check-points (Fig. 8). One of them requires a pilot before reaching the set ground object to make a turn and continue the flight to the next ground object (Fig. 8, aircraft no. 1). Another method involves a pilot doing a fly-over over the set ground object $E$, making a turn and returning to the path from object $E$ to object $F$ (Fig. 8, aircraft no. 2). However, for pilots of aircraft no. 1 and no. 2 it would be equally difficult to complete such flight turns. It is therefore suggested to do the turns according to flight trajectory of aircraft no. 3. This aircraft pilot has made a $90^{\circ}$ turn and flown to ground object $G$.

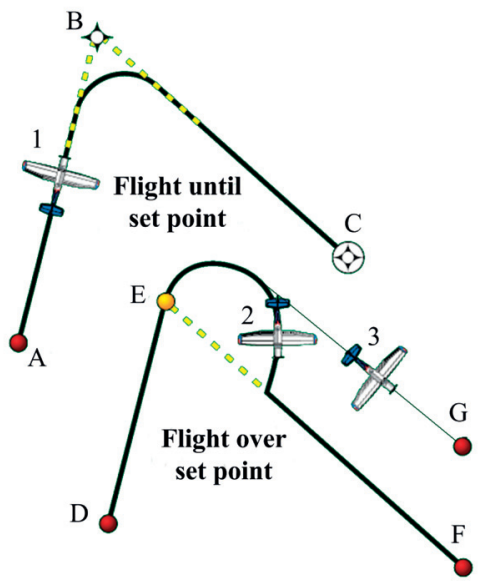

Fig. 8. Assessment of pilot flight when the pilot is flying near or over flight points

Figure 9 presents the left and the right superelevation (eight shape) flight assessment corridor. It is often used in training flights, but has not been formally described. The aim of using this corridor for assessment is to assess the pilot's skills to perform a circle shape right flight turn under conditions involving vortexes, wind drift and other impending factors.

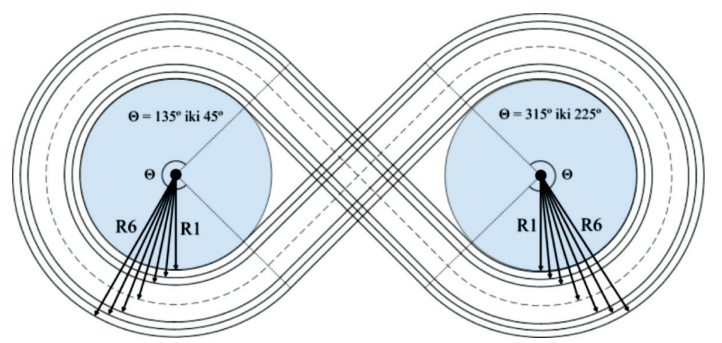

Fig. 9. Left and right superelevation performance in flight assessment corridor

A different flight assessment methodology similar to that in figure 9 could also be used for flight assessment. It involves the performance of upward or downward spiral with varying angles of rolls (e.g. $15^{\circ}, 30^{\circ}$, $45^{\circ}$ ). Using this method, a pilot's ability to maintain a nice banking at wind drift, and the ability to maintain a steady climb or descent angle a (e.g. $5^{\circ}, 10^{\circ}, 15^{\circ}$ ) (Fig. 10) are assessed. For this type of a flight assessment corridor may be designed as well.

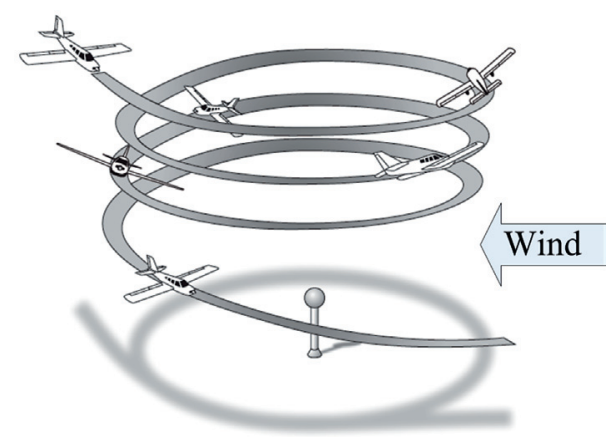

Fig. 10. A steady downward spiral at wind drift 
Visually it is difficult for an aircraft pilot to make accurate turns, especially with wind drift. Therefore, prior to the flight, the aircraft pilot should familiarize himself with the set trajectory and the turn corners must be pre-calculated in accordance with equations (5) and (6), because certain turning performance depends on aircraft roll and speed (for higher speed higher radius of the turn is required). It is, therefore, necessary to provide the pilot with the turn performance parameters: bank angle $\Theta$ (Fig. 11) and speed v. Currently, the assessment boundaries are difficult to define because it is necessary to carry out experimental studies and statistical analysis of the accuracy at which pilots are able to perform such tasks.

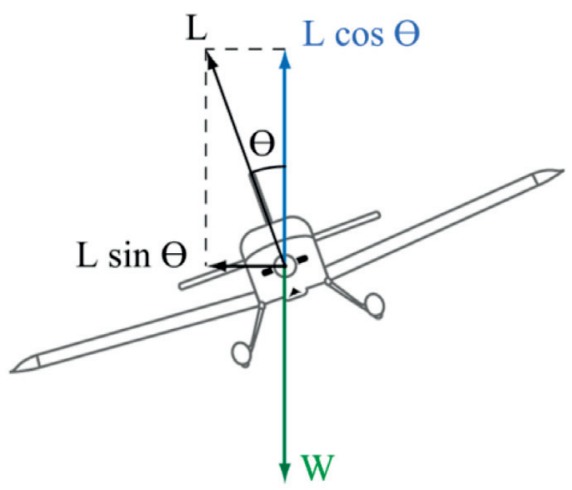

Fig. 11. Acting forces on aircraft when pilot is banking (flies with bank)

$$
\begin{aligned}
& (x) L \cdot \sin \theta=m \cdot \frac{v^{2}}{R} ; \\
& (y) L \cdot \cos \theta=m \cdot g .
\end{aligned}
$$

From (5) and (6) we get the equation (7):

$$
g \cdot \tan \theta=\frac{v^{2}}{R},
$$

where $L$ is lift force; $\Theta$ - aircraft bank angle; $m$ - aircraft weight; $v$ - aircraft speeds; $R$ - turning radius; $g$ - free fall acceleration of gravity.

If turning radius and bank angle of the aircraft are known, aircraft air speed can be calculated by equation (8), which is derived from equation (7):

$$
v=\sqrt{R \cdot g \cdot \tan \theta} .
$$

If turning radius and air speed of the aircraft are known, aircraft bank can be calculated by the following equation (9):

$$
\theta=\operatorname{actan}\left(\frac{v^{2}}{R \cdot g}\right) .
$$

If aircraft air speed and bank angle are known, a turning radius can be calculated from the following equation (10):

$$
R=\frac{v^{2}}{g \cdot \tan \theta} .
$$

In order to increase accuracy of flight assessment, it is necessary to consider not only the flight trajectory points that went beyond the limits of the assessment, but to take each point as an object which occupies a certain volume.

If a GPS antenna is mounted on the aircraft rear window, as shown in the aircraft horizontal projection (Fig. 12), the length $x 2$ from antenna to front of the aircraft and length $x 1$ from antenna to the aircraft tail should be measured. The same must be carried out with the wingspan, i.e. distances $y 1$ and $y 2$ are required.

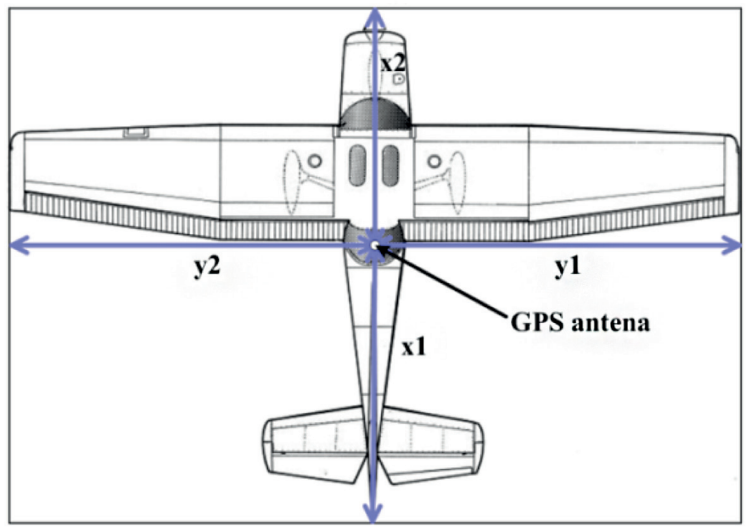

Fig. 12. Point of measurement (GPS antenna location) on the aircraft in the horizontal projection

In the vertical projection of the aircraft (Fig. 13), the height from the ground to the GPS antenna and the height from the GPS antenna to the tips of aircraft vertical stabilizer need to be measured and the measured data should be entered into an automatic pilot flight assessment system.

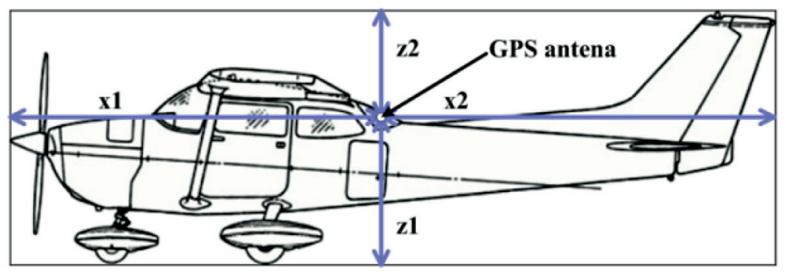

Fig. 13. Measurement point (GPS antenna location) on the aircraft in the vertical projection

Figure 14 illustrates different flight paths kept by pilots of three aircrafts. Pilot from aircraft no. 1 flies exactly according to a set trajectory. Pilot from aircraft no. 2 flies a bit away from a set trajectory, but still maintains the trajectory sufficiently for the assessment to remain the maximum. If aircraft is assessed as a point, the pilot from aircraft no. 3 still does not cross the maximum rating threshold line. However, the aircraft as an object which occupies a certain volume should be assessed as being in the left-hand side of the wing span $y 2$ in figure 12. Therefore, according to this criterion the assessment of the third aircraft pilot rating would be below the 
maximum score. When the aircraft is assessed as an object, it is also important to assess aircraft dimensions by adding or subtracting the obtaining GPS coordinates to or from the data:

Aircraft coordinates $\pm x 1$

Aircraft coordinates $\pm x 2$

Aircraft coordinates $\pm y 1$

Aircraft coordinates $\pm y 2$

Aircraft coordinates $\pm z 1$

Aircraft coordinates $\pm z 2$

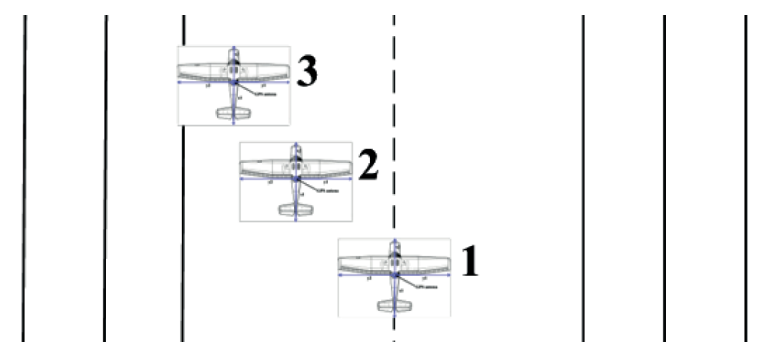

Fig. 14. Various positions of aircraft in pilot flight assessment corridor

The aircraft could be assessed as a point, however the flight assessment would be less accurate, hence the assessment corridors would need to be widened.

Considering the volume of the aircraft, measurements of each aircraft used in training flights would need to be known and pre-entered into the system so that the dimensions of the aircraft structure could be included.

Flight prediction is also required since the flight cannot be solely based on measurements. According to the methods used by P. B. Ober, the flight assessment system, using prognostication methods, could monitor critical pilot manoeuvres and react to them accordingly (Fig. 15) (Ober et al. 1998).

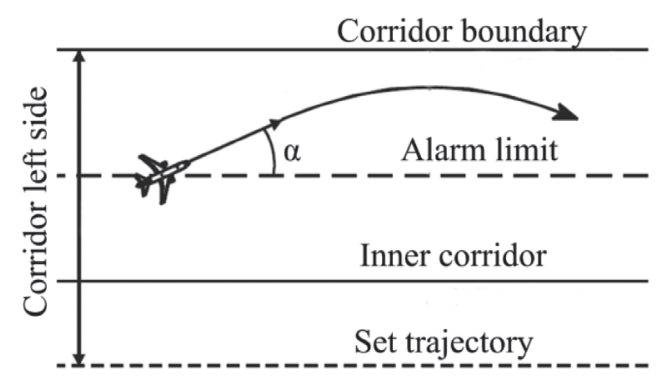

Fig. 15. Aircraft pilot flight prognostication

This requires the system to monitor aircraft air speed and angle $\alpha$ from the set trajectory. It would then be possible to predict the expected aircraft movement trajectory and according to this to assess a flight and warn about critical flight manoeuvres.

\section{Conclusions}

1. After the analysis of assessment methods of training flights, new aspects of flight assessment methods suitable for automatic pilot flight assessment system were reviewed.

2. Experimental flights must be carried out for the methods of pilot flight assessment proposed in the article, which would permit to statistically determine how accurately the pilots are able to perform the tasks, according to which subsequently the advanced pilots could be deduced.

3. In order to increase the accuracy of flight assessment, it is necessary to assess the aircraft not as a point but as an object that occupies a certain volume in space.

4. According to aircraft airspeed and deviation angle from a set trajectory, it is possible to predict aircraft flight trajectory and assess the critical manoeuvres of the aircraft pilot.

\section{References}

Bahcivan, Z.; Koyuncu, E.; Aydin, S. S., et al. 2011. ITU/AU air traffic control network simulator for design, development and testing of automated ATM systems, in Ataccs 2011hala! Research Network First Annual Conference.

Bourgois, M.; Copper, M.; Duong, V., et al. 2005. Interactive and Immersive 3D Visualization for ATC. Norrköping Visualization and Interaction Studio, Linköpings Universitet, Norrköping, Sweden.

Funabiki, K.; Iijima, T. 2007. Attention allocation in Tunnelin-the-Sky on HUD and HDD for visual flight, in Digital Avionics Systems Conference, DASC '07. IEEE/AIAA $26^{\text {th }}$.

Herndon, A. A.; Cramer, M.; Sprong, K. 2008. Analysis of advanced flight management systems (FMS), flight management computer (FMC) field observations trials, radius-to-fix path terminators, in 2008 IEEE/AIAA 27th Digital Avionics Systems Conference.

Lobanova, L. 1997. Factors of evaluation of quality of aviation specialists training, in International Scientific Applied Conference devoted to 70 years of Lithuanian Air Club, AVIATION-97. Conference Proceedings. Vilnius: Technika, 106-108.

Ober, P. B.; Theunissen, E.; Meijer, R. C., et al. 1998. RNP requirements for 4-D navigation, in Proceedings of the ION-GPS98 Conference, Nashville, Tennessee, USA, 15-18 September, 1998.

Savičiene, L. 2011. Operationalization of Norms for Aircraft Approach and Departure in the SKY-scanner DSS. Paris: IRIT press, 79-88.

Stankūnas, J. 1997. Preparation of aviation specialists for the Air Force, in International Scientific Applied Conference devoted to 70 years of Lithuanian Air Club, AVIATION-97. Conference Proceedings. Vilnius: Technika, 32-36. 